\title{
O USO DE ARTEFATOS HISTÓRICOS NA EDUCAÇÃO DE JOVENS E ADULTOS
}

\section{THE USE OF HISTORICAL ARTIFACTS IN YOUTH AND ADULT EDUCATION}

\author{
Viviane Sousa da Silva \\ Universidade Federal da Paraíba - UFPB \\ Cristiane Borges Angelo ${ }^{2}$ \\ Universidade Federal da Paraíba - UFPB
}

\section{Resumo}

Este trabalho apresenta os resultados de uma pesquisa que teve por objetivo geral investigar a contribuição da História da Matemática na Educação de Jovens e Adultos (EJA), mediante o uso de artefatos matemáticos históricos utilizados em atividades planejadas com essa finalidade. Mais precisamente, visando diminuir as dificuldades com a matemática que os alunos da EJA enfrentam em sala de aula, elaboramos, desenvolvemos e avaliamos uma proposta com atividades para a EJA que abordou conteúdos da História da Matemática mediante a utilização de artefatos históricos. Para fundamentar este trabalho nos embasamos nos Parâmetros Curriculares Nacionais (BRASIL, 1998) e autores como D’Ambrósio (1999), Fonseca (2012), Mendes (2001), Oliveira (2009). Foi uma pesquisa qualitativa e exploratória, realizada com 25 alunos, do Ensino Médio da EJA, de uma Escola Pública Estadual do Município de Mamanguape, na Paraíba. A investigação foi desenvolvida em três etapas, a saber: (1) elaboração das atividades utilizando artefatos históricos; (2) desenvolvimento da proposta das atividades na Educação de Jovens e Adultos; (3) avaliação das potencialidades e limitações da proposta das atividades históricas, através da utilização do instrumento questionário. Como resultados constatamos que é possível trabalhar com os artefatos históricos na EJA, desde que o professor faça um planejamento de como estas atividades serão desenvolvidas em sala de aula; que na EJA ainda existe uma enorme carência com relação à aprendizagem matemática; que apesar das dificuldades apresentadas pelos alunos as aulas foram bastante produtivas e os alunos muito participativos, sempre dialogando com os colegas sobre as atividades trabalhadas em sala. Concluímos que o uso de artefatos históricos pode contribuir no processo e aprendizado do aluno, permitindo que o sujeito interaja e troque ideias com o professor e os seus colegas, fazendo assim com que as aulas sejam mais produtivas e dinâmicas. Concluímos também que é importante que o professor perceba que pode utilizar a História da Matemática com outras metodologias, a exemplo dos materiais manipulativos, utilizados nesse trabalho.

Palavras-chave: História da Matemática; Educação de Jovens e Adultos; Artefatos Históricos.
Abstract
${ }^{1}$ vivimmesousa@hotmail.com
${ }^{2}$ cristianeangelo@dce.ufpb.br 
This paper presents the results of a research that had as general objective to investigate the contribution of History of Mathematics in the Education of Youth and Adults (EJA), through the use of historical mathematical artifacts utilized in activities planned with this finality. More precisely, in order to reduce the difficulties with mathematics that the students of EJA face in the classroom, we elaborated, developed and evaluated a proposal with activities for EJA that approached contents of History of Mathematics through the use of historical artifacts. In order to substantiate this work, we based ourselves on the National Curricular Parameters (BRASIL, 1998) and authors such as D'Ambrósio (1999), Fonseca (2012), Mendes (2001) and Oliveira (2009). It was a qualitative and exploratory research, carried out with 25 students, of the EJA High School, of a State Public School of the Municipality of Mamanguape, Paraíba.The research was developed in three stages (1) elaboration of the activities using historical artifacts, (2) development of the proposal of activities in Youth and Adult Education; (3) evaluation of the potentialities and limitations of the proposal of historical activities, through the use of the questionnaire instrument. As a result we found that it is possible to work with the historical artifacts at EJA, as long as the teacher makes a plan of how these activities will be developed in the classroom; that at EJA there is still a great lack of mathematical learning; that despite the difficulties presented by the students, the classes were very productive and the students very participative, always talking with their colleagues about the activities worked in the classroom. We conclude that the use of historical artifacts can contribute to the student's process and learning, allowing the subject to interact and exchange ideas with the teacher and his colleagues, thus making classes more productive and dynamic. We conclude also that it is important that the teacher realize that he can use the History of Mathematics with other methodologies, like the manipulative materials used in this work.

Keywords: History of Mathematics; Youth and Adult Education; Historical Artifacts.

\section{Introdução}

Este trabalho apresenta os resultados de uma pesquisa que teve por objetivo geral investigar a contribuição da História da Matemática na Educação de Jovens e Adultos (EJA), mediante o uso de artefatos matemáticos históricos utilizados em atividades planejadas com essa finalidade. Mais precisamente, visando diminuir as dificuldades com a matemática que os alunos da EJA enfrentam em sala de aula, elaboramos, desenvolvemos e avaliamos uma proposta com atividades para a EJA que abordou conteúdos da História da Matemática mediante a utilização de artefatos históricos.

A escolha pelo público da EJA ocorreu tendo em vista que, no Brasil, essa modalidade de ensino vem apresentando muitas lacunas na aprendizagem da disciplina de Matemática. Essas lacunas, muitas vezes, são evidenciadas pelos docentes nas aulas 
de Matemática, o que nos leva a pensar sobre o modo como o ensino da Matemática está sendo desenvolvido em sala de aula.

Considerando que existem vários caminhos para se fazer Matemática em sala de aula (BRASIL, 1998), optamos por trabalhar na EJA com os artefatos históricos com o intuito de contribuir para que o estudante possa aproximar-se da Matemática.

\section{Os pressupostos metodológicos da pesquisa}

Esta pesquisa caracteriza-se como uma pesquisa qualitativa que, segundo Gonçalves (2005, p. 65), “[...] tem como objeto o estudo de uma unidade de forma aprofundada, podendo tratar-se de um sujeito, de um grupo de pessoas, de uma comunidade etc."

Com relação aos objetivos, essa pesquisa é exploratória. Esse tipo de pesquisa, segundo Gil (2002, p. 27), “tem como propósito proporcionar maior familiaridade com o problema, com vistas em torná-lo mais explícito ou construir hipóteses”.

Quanto aos procedimentos, essa pesquisa se configura em um estudo de caso, realizado por meio de uma intervenção realizada em uma instituição pública pertencente à rede estadual de ensino da Paraíba, localizada no município de Mamanguape.

Essa pesquisa foi realizada em uma turma da EJA, do turno noite. A referida turma contava com 25 alunos, na faixa etária entre 17 e 41 anos, sendo um aluno com 17 anos, seis alunos com 18 anos, um aluno com 21 anos, dois alunos com 22 anos, cinco alunos com 23 anos, dois alunos com 24 anos, um aluno com 26 anos, um aluno com 28 anos, dois alunos com 29 anos, um aluno com 30 anos, um aluno com 31 anos, um aluno com 32 anos e um aluno com 41 anos. Com relação ao gênero, a sala estava dividida em onze alunos do sexo feminino e quatorze alunos do sexo masculino.

A investigação foi desenvolvida em três etapas, a saber: na primeira etapa adaptamos as atividades históricas utilizando artefatos históricos, elaboradas em forma de cadernos temáticos e utilizadas no projeto Prolicen $2015^{3}$. No segundo momento desenvolvemos a proposta das atividades na Educação de Jovens e Adultos. No terceiro momento avaliamos as potencialidades e limitações da proposta das atividades

\footnotetext{
${ }^{3}$ As atividades históricas foram adaptadas dos cinco cadernos temáticos que foram produzidos em 2015 , no projeto "O uso de artefatos históricos na EJA: uma proposta para a formação continuada de professores de Matemática". Como nessa experiência de 2015 os cadernos temáticos tinham como público alvo professores que ensinavam Matemática na EJA, adaptamos as atividades para serem trabalhadas especificamente com alunos da EJA do Ensino Médio.
} 
históricas, através da utilização do instrumento questionário. A opção por utilizar questionário se deu por esse instrumento ser definido como “[...] uma técnica pra obtenção de informações sobre sentimentos, crenças, expectativas, situações vivenciadas e sobre todo e qualquer dado que o pesquisador (a) deseja registrar para atender os objetivos de seu estudo" (OLIVEIRA, 2007, p. 83). Assim, após termos desenvolvido as atividades propostas para o público da EJA, e mostrar a eles a importância da história da Matemática via artefatos históricos, convidamos os alunos a preencher o instrumento de pesquisa.

\section{O uso de artefatos na EJA}

Considerando que "aprender matemática é um direito básico de todos e uma necessidade individual e social de homens e mulheres" (BRASIL, 2002 p. 11) e que "saber calcular, medir, raciocinar, argumentar, tratar informações estatisticamente etc. são requisitos necessários para exercer a cidadania" (BRASIL, 2002 p. 11), percebemos a importância que a Matemática tem na vida dos estudantes da EJA.

Dessa forma e considerando o perfil de estudantes que frequentam a EJA devemos, enquanto educadores, pensar em estratégias que possibilitem que esse público consiga ser incentivado para aprender Matemática. De modo especial, é preciso que os educadores matemáticos para a EJA tenham uma intimidade com a Matemática, declarada em diversos momentos sempre na busca de oferecer ao público da EJA estratégias mais eficazes, para que os alunos possam adquirir a vontade de aprender Matemática.

A responsabilidade em promover um ensino de qualidade para a EJA, vai ao encontro de propiciar oportunidades favoráveis aos alunos proporcionando “[...] experiências de significação passíveis de serem não apenas vivenciadas, mas também apreciadas pelo aprendiz" (FONSECA, 2012, p. 25), além de permitir e proporcionar uma dimensão de conhecimentos vivenciados conscientemente pelo aluno.

Assim, elaboramos uma proposta de ensino, via história da matemática com artefatos históricos, visando oferecer a esse público caminhos para que todos permaneçam em sala de aula e construam novos conhecimentos, tendo em vista que "o recurso à história pode dar respostas a alguns porquês, esclarecendo e dando significado às ideias matemáticas que estão sendo construídas nas aulas pelos jovens e adultos" 
(BRASIL, 2002, p. 28). Desta forma, buscamos desenvolver meios diversificados de trabalhar a disciplina de matemática em sala de aula e proporcionar aos alunos aulas mais interativas e prazerosas.

Consideramos que a História da Matemática é uma perspectiva metodológica que pode auxiliar no ensino trazendo para o aluno possibilidades de um contato mais favorável com a matemática, oferecendo uma contribuição ao processo de ensino e aprendizagem, tendo em vista que o aluno pode compreender os motivos pelos quais essa ciência foi sendo elaborada ao longo dos tempos.

Conforme D’Ambrósio (1999, p. 97), a História da Matemática é uma ferramenta metodológica para o ensino, pois:

[...] as práticas educativas se fundam na cultura, em estilos de aprendizagem e nas tradições, e a história compreende o registro desses fundamentos. Portanto, é praticamente impossível discutir educação sem recorrer a esses registros e a interpretação dos mesmos. Isso é igualmente verdade ao se fazer o ensino das várias disciplinas. Em especial da Matemática, cujas raízes se confundem com a história da humanidade.

Mendes (2001, p. 68) também enfatiza a história como recurso auxiliar para aulas de matemática e afirma que sua finalidade é “[...] promover um ensinoaprendizagem da matemática que busque dar uma ressignificação ao conhecimento matemático produzido pela sociedade ao longo dos tempos”.

Desta forma, ao inserir como recurso metodológico a História da Matemática podemos contribuir de maneira positiva para o desenvolvimento e conhecimento do aluno a partir dos conteúdos proposto em sala de aula.

Com relação à forma de se trabalhar a História da Matemática em sala de aula, Mendes (2009) propõe um modelo de atividades históricas para uso em sala de aula, a partir experiências manipulativas e visuais. Esse modelo, segundo o autor, “[...] parte do princípio que as experiências manipulativas ou visuais do aluno contribuem para que se manifestem nele as primeiras impressões do conhecimento apreendido durante a interação sujeito-objeto [...]" (MENDES, 2009, p. 118).

O modelo adotado para as atividades históricas (MENDES, 2009) e utilizado nesse trabalho é composto dos seguintes itens: nome de cada atividade, os objetivos das atividades, o conteúdo histórico, o material a ser utilizado nas atividades, a operacionalização das atividades, os desafios propostos nas atividades, o exercício da 
sistematização e formalização do conhecimento e, se necessário, a oferta de atividades complementares.

As atividades históricas permitem que o aluno tenha experiências manipulativas e visuais no processo de aprendizagem matemática. Esse tipo de utilização da história da matemática está vinculada ao seu uso manipulativo que, segundo Fossa (2001, p. 55) é "[...] uma das maneiras mais eficazes de ensinar Matemática - especialmente, mas não exclusivamente, para alunos jovens [...] através de atividades estruturadas utilizando materiais manipulativos".

Assim, acreditamos que ao utilizar os artefatos históricos, que se constituem em materiais manipulativos e/ou visuais, estaremos auxiliando os alunos na compreensão dos conteúdos matemáticos. Estamos entendendo nessa pesquisa artefatos históricos como "[...] objetos que representam valores simbólicos criados pelo homem num determinado espaço e tempo da história, e que, portanto, são dotados de significados dentro de um contexto cultural e social" (OLIVEIRA, 2017, p. 72). Nesse sentido, artefatos históricos podem ser instrumentos, documentos, imagens, dentre outros que, de alguma forma, contam a história da matemática ao longo dos tempos.

Nesse sentido, a opção por trabalhar com o uso de artefatos históricos na EJA, justifica-se porque com esse tipo de material podemos promover uma postura mais ativa do aluno frente ao conteúdo matemático. Nessa perspectiva, ao possibilitar que o aluno conheça e manuseie um artefato histórico, estamos também possibilitando que o aluno construa seu saber. Assim, acreditamos que a proposta de trabalhar os artefatos históricos na EJA, “irá promover a reflexão de aspectos relacionados à Matemática que rompam com a visão de uma ciência abstrata, absoluta e universal, coadunando para uma visão de ciência viva, atrelada a determinados contextos socioculturais". (SILVA; NASCIMENTO; SILVA; NASCIMENTO; ANGELO, 2015, p. 7).

\section{As atividades propostas}

Optamos por apresentar atividades históricas, utilizando artefatos históricos, com o objetivo de investigar a contribuição do uso de artefatos históricos na Educação de Jovens e Adultos. Logo após as atividades, avaliamos a proposta por nós elaborada e ministrada, por meio de um questionário final. 
Ao todo foram realizadas cinco atividades históricas, em encontros com duração de duas horas-aula, cada um. No último encontro, aplicamos um questionário com a finalidade de avaliar a experiência e verificar as potencialidades e limitações do uso de artefatos históricos na EJA.

A primeira atividade teve como título "Egípcios: os inovadores matemáticos". Nessa atividade trabalhamos o artefato histórico Papiro Rhind. Os objetivos dessa atividade foram: Contextualizar a matemática praticada no antigo Egito; mostrar as diversas situações matemáticas presentes no Papiro Rhind; e aproximar a matemática do aluno. O conteúdo histórico da atividade consistiu na importância que os povos do Egito Antigo tiveram na construção da Matemática, destacando como a aritmética, a álgebra e a geometria eram percebidas e trabalhadas pelos egípcios na Antiguidade.

A segunda atividade apresentada para a turma teve como título "Os símbolos e a numeração egípcia". O artefato histórico abordado nessa atividade foram os símbolos do sistema de numeração egípcios. Os objetivos dessa atividade foram: Conhecer o sistema de numeração egípcio e comparar o sistema de numeração egípcio com o sistema de numeração decimal. O conteúdo histórico da atividade consistiu na apresentação dos símbolos numéricos adotados no sistema de numeração que os egípcios utilizavam, destacando cada símbolo egípcio.

A terceira atividade teve como título a "Álgebra geométrica nos elementos de Euclides". O objetivo dessa atividade foi mostrar aos alunos a álgebra por meio da geometria. Foram utilizados o material manipulativo Algeplacas e o artefato histórico correspondente ao livro "Os Elementos", uma das obras mais importantes da cultura ocidental, em que o autor compila e sistematiza o conhecimento matemático da época clássica. O conteúdo histórico da atividade consistiu em destacar para os alunos a importância de se conhecer o matemático grego Euclides, e explicar-lhes como Euclides representava objetos geométricos através de objetos algébricos, e as operações geométricas por meio de operações algébricas.

A quarta atividade teve como título "O quipu inca: uma engenhosa invenção de cálculo" e, como o próprio título da atividade sinaliza, o artefato histórico abordado foi o quipu. Os objetivos dessa atividade foram: Contextualizar a civilização inca; Conhecer o artefato inca "quipu", confeccionar o artefato e realizar atividade com o instrumento confeccionado. O conteúdo histórico da atividade consistiu na importância 
de conhecer toda a explanação sobre a cultura inca e sobre o quipu, destacando também como se constrói o artefato.

A quinta atividade teve como título "Os símbolos maias". O artefato histórico utilizado nessa atividade foram os símbolos numéricos utilizados na civilização Maia. Os objetivos dessa atividade foram: Contextualizar a civilização Maia; Conhecer alguns artefatos maias; e conhecer o sistema de numeração maia. O conteúdo histórico da atividade consistiu na importância de conhecer o Sistema de Numeração que os Maias utilizavam, destacando cada símbolo maia.

\section{Os resultados da experiência}

Conforme mencionado anteriormente, utilizamos o questionário para avaliarmos as potencialidades e limitações do uso de artefatos históricos na EJA. Esse questionário compreendia oito questões relacionadas ao tema de pesquisa e a análise das respostas será apresentada a seguir ${ }^{4}$.

A primeira questão perguntava aos alunos se eles já tinham ouvido falar ou conheciam algum artefato histórico. Se a resposta fosse positiva, a questão solicitava que os alunos indicassem qual o artefato conhecido.

Como respostas, observamos que três alunos afirmaram que já conheciam um artefato histórico trabalhado em sala de aula, conforme podemos observar nos relatos elencados a seguir:

Sim, em uma atividade que falava sobre o quipu. (A17).

Sim, Já ouvi falar sobre os números egípcios estudei o ano todo em uma escola no Rio de Janeiro. (A22).

Sim, sobre os quadros do Museu. (A25).

Os demais dos vinte e um alunos da turma afirmaram nunca terem ouvido falar sobre artefatos históricos. Podemos observar esse fato nos três registros destacados a seguir:

Não, eu nunca tinha visto falar. (A1).

Não, eu estou vendo pela primeira vez em sua aula Professora. (A6).

Não, artefatos antigos sobre matemática é novidade pelo menos em relação a minha pessoa. (A8). $\mathrm{A} 25$.

${ }^{44}$ Para efeito de identificação dos alunos serão utilizadas a seguinte simbologia: A1, A2, A3, ..., 
Observamos nas respostas dos alunos que a história da Matemática pouco se faz presente nas salas de aula. Esse fato ratifica os resultados da pesquisa desenvolvida por Feliciano (2008) que constatou que, apesar de os professores de Matemática reconhecerem a importância do uso da história dessa disciplina em sala de aula, não demonstram utilizar, de fato, a História da Matemática como recurso pedagógico.

A segunda questão perguntava aos alunos se o desenvolvimento das atividades com o auxílio da História da Matemática via Artefatos Históricos trouxe alguma contribuição de aprendizagem eles. Se a resposta fosse positiva, a questão solicitava que os alunos relatassem quais contribuições.

Como respostas, observamos que dos vinte e cinco alunos respondentes, vinte e três alunos afirmaram que tiveram contribuições para a sua aprendizagem e dois alunos deixaram essa questão em branco. A seguir elencamos algumas respostas obtidas na segunda questão.

Sim, contribuiu bastante por que é uma atividade diferente, onde traz novos conhecimentos. (A2).

Sim, pois facilita mais os nossos conhecimentos se aprofundando sobre o assunto. (A8).

Sim, por que tudo que a gente aprende é importante para o nosso futuro e para a nossa vida. (A9).

Sim, por que assim aprendi um pouco mais sobre a história da matemática. (A10).

A esse respeito podemos ressaltar que a história da matemática é importante e fundamental para que os alunos conheçam diversas maneiras de aprendizagem. Dessa forma, segundo Gutierre (2011, p. 25), “[...] ajudar o aluno a compreender diversas faces de um mesmo problema, permitirá que compreenda o que há de comum nas diversas soluções."

A terceira questão perguntava aos alunos quais pontos eles destacariam como positivos nas atividades e quais pontos destacariam como negativos. Se a resposta fosse positiva ou negativa a questão solicitava que os alunos relatassem.

Dos vinte e cinco alunos, vinte responderam a questão, os demais deixaram em branco. Das respostas obtidas, dezoito alunos alegam como fator positivo que nesse tipo de atividade a possibilidade de aprender algo novo e observar como a matemática foi construída, conforme podemos observar nos relatos a seguir: 
Os pontos positivos foram em aprender coisas novas, diferentes das que eu já tinha estudado. (A3).

Os pontos positivos foram em poder ver novas formas de aprender a matemática. (A6).

Os pontos positivos foi intender como funcionava a matemática antigamente. (A22).

Das respostas obtidas, dezoito dos alunos também alegam quais os fatores que encontraram como negativos na atividade: o fato de desconhecerem os artefatos, o pouco tempo de aula e a dificuldade, algumas vezes encontrada, de entender o artefato matematicamente, conforme podemos observar nos registros a seguir.

Os pontos negativos foram fazer algumas atividades sobre os artefatos históricos, pois eu nunca tinha ouvido falar. (A3).

Os pontos negativos foi um pouco complicado para entender todas as atividades em pouco tempo. (A6).

Os pontos negativos foi entender como funcionava todos os artefatos. (A22).

Além disso, sete alunos relataram que tiveram dificuldades por falta de conhecimento sobre a história da matemática. Conforme podemos observar a seguir:

Nunca ouvi falar sobre a história da matemática. (A5).

Foi um pouco complicado para entender sobre a história da matemática, tive dificuldades por nunca ter visto. (A7).

É muito estranho estudar matemática com artefatos históricos via história da matemática por nunca ter visto. (A10).

Nesse caso podemos conjecturar que ainda há dificuldade dos alunos em realizar atividades envolvendo a história da matemática via artefatos históricos. A esse respeito "[...] sugerimos que o professor também explore adequadamente os artefatos históricos no trabalho com a atividade de ensino, como elemento integrador desse diálogo, tendo em vista que podem ajudar o aluno a compreender o momento histórico em que foi construído o conhecimento." (OLIVEIRA, 2009, p. 83).

A quarta questão perguntava aos alunos qual o artefato histórico que eles haviam mais gostado de conhecer e qual havia lhe ajudado mais a compreender o conteúdo matemático. Vinte e quatro alunos responderam essa questão. Dois alunos afirmaram terem gostado mais dos símbolos maias, nove alunos gostaram mais do artefato quipu, 
quatro alunos afirmaram terem gostado mais dos números egípcios, dois alunos optaram em sua resposta pelas algeplacas e sete alunos relatam que gostaram de todos os artefatos históricos. Alguns dos depoimentos dos alunos em relação a essa questão foram destacados a seguir:

O quipu, por que foi o melhor de se compreender através da história da matemática. (A4).

Os símbolos egípcios por que é bem mais prático e interessante para aprender. (A7).

Gostei de todos, são ótimos para se aprender novos conhecimentos. (A13).

Os símbolos maias por que achei bem interessante, uma nova forma de usar os números. (A20).

Oliveira (2009, p. 86) enfatiza a importância da utilização de uma variedade de artefatos históricos que podem ser abordados em sala de aula. De acordo com a autora, em situação de aula esses artefatos oportunizam aos alunos:

[...] momentos de reflexão e de aproximação dele com uma realidade que aconteceu num tempo bem distante. Através dos acontecimentos históricos (artefatos), o aluno entra em contato com as linguagens e formas de pensar de outras épocas, o que de certa forma, contribui para que o aluno perceba a ação do homem, produzindo conhecimentos e as mudanças o corridas ao longo do tempo.

A quinta questão perguntava para os alunos se houve algum artefato histórico que dificultou o seu entendimento sobre o conteúdo matemático. Dos vinte e cinco alunos, seis não responderam essa questão.

Dos alunos que responderam, dez afirmaram que não tiveram nenhuma dificuldade com os artefatos, um aluno afirmou que teve dificuldade com os símbolos maias, seis alunos afirmaram que sentiram dificuldade com o artefato quipu, quatro alunos com os símbolos egípcios e três alunos tiveram dificuldades com as algeplacas, conforme podemos verificar em alguns relatos, descritos a seguir:

Não tive dificuldades, todos foram muito importantes para os meus conhecimentos. (A2).

Sim tive muita dificuldade para entender os símbolos maias. (A14). Sim, o quipu foi o artefato que tive mais dificuldades, pois não conseguia entender como se fazia o nó na posição correta. (A20). Sim, porque eu fiquei com muita dificuldade com os símbolos da numeração egípcia. (A4). 
Sim, os algeplacas porque eu senti dificuldades em compreender os conteúdos matemáticos. (A1).

Nesse caso, observamos que segundo Gutierre (2011, p. 31)

[...] não queremos que o aluno percorra todo o percurso que nossos antepassados tiveram de fazer até chegar ao nível atual de descobertas, mas queremos desafiá-lo em termos de estratégias do pensamento, por meio de uma dinâmica, oferecendo-lhes recursos pedagógicos por meio das atividades elaboradas que favoreçam a reconstrução e apropriação dos conhecimentos.

A sexta questão perguntava aos alunos se o uso de artefatos históricos ajudou a compreender melhor os conteúdos matemáticos. Dos vinte e cinco alunos, vinte e três relataram que com o uso dos artefatos históricos fica mais fácil de compreender os conteúdos matemáticos, embora três não tenham justificado suas respostas. Nos relatos elencados a seguir, podemos observar algumas das justificativas apresentadas:

Sim, por que é importante aprender outros conteúdos, pois nunca tinha estudado esses artefatos foi mais uma aprendizagem. (A20).

Sim, por que é um modo mais divertido de aprender os conteúdos matemáticos. (A9).

Sim, por que abre mais a nossa mente com relação aos conteúdos que estamos estudando. (A1).

Dois disseram que os artefatos não ajudaram no entendimento do conteúdo matemático e três afirmaram que ajudou, mas não justificaram a resposta. A justificativa dada pelos alunos que afirmaram que os artefatos não ajudaram no entendimento estão apresentadas a seguir.

Não, pois hoje em dia temos meios mais fáceis de fazer cálculos. (A22).

Não, por que ficar complicado para aprender os cálculos do passado. (A13).

Nessa perspectiva de ensino é preciso que o educador tenha estratégias de conhecimentos matemáticos para que o aluno se sinta envolvido em cada conteúdo proposto para que possa propiciar “"[...] momentos de construção do conhecimento, pois o aluno aprende a partir da participação direta da experiência proposta e levanta hipóteses que conduzem a um aprofundamento do conceito estudado" (OLIVEIRA, 
2009, p. 100). Assim, o papel do professor será significativo para o ensino e aprendizagem da matemática.

A sétima questão perguntava aos alunos se eles gostariam que o professor desse continuidade na sala de aula com atividades utilizando a história da Matemática via artefatos históricos. Dos vinte e cinco alunos, vinte e três disseram que sim conforme podemos ver nos relatos a seguir:

Sim, por que facilita o entendimento do conteúdo matemático. (A14). Sim, por que gostei muito e achei interessante aprender esses artefatos, gostaria de aprender bem mais sobre esses assuntos. (A20). $\mathrm{Sim}$, achei muito interessante e gostaria de aprender mais com o meu professor as aulas iriam ficar mais divertidas. (A18).

Dois alunos afirmaram que não gostariam, porque o conteúdo ficaria mais complicado para se entender, de acordo com os relatos a seguir.

Não, porque é um pouco complicado. (A22).

Não, prefiro a aula normal com os conteúdos atuais, assim fica mais difícil. (A6).

Ao refletir sobre o uso da história da Matemática em sala de aula, Mendes (2001, p. 25) afirma que "[...] é muito importante que essas experiências, [...] sejam orientadas pelo professor, sempre que for necessário, para que possa levá-los a formular conceitos e/ou propriedades e interpretar essas formulações visando aplicá-las na solução de problemas práticos que assim o exijam.”

$\mathrm{Na}$ oitava questão deixamos os alunos à vontade para registrarem a sua avaliação com relação às aulas, destacando os pontos positivos e negativos. Dos vinte e cinco alunos, 23 gostaram das aulas e relataram que foram momentos de aprendizagem de todos, conforme podemos observar a seguir:

As aulas da professora foram muito boas, ela explicar muito bem, nos trouxe artefatos históricos ótimos coisas que nós nunca tinha visto. (A7).

Gostei muita das aulas por que foram muito produtivas e a professora contribui-o bastante com as explicações. (A9).

Gostei muito das aulas, por que a professora foi muito atenciosa com todos os alunos. (A12).

Não tem pontos negativos a professora foi ótima, suas aulas foram bem explicadas tudo perfeito uma ótima professora os assuntos que ela trouxe foram uma maravilha. (A10). 
Um aluno não respondeu essa questão e um aluno encontrou um ponto negativo, conforme relato a seguir:

O ponto negativo é que o assunto com artefatos históricos é diferente do nosso complicando um pouco o assunto. (A11).

A esse respeito, "acreditamos que o ato de ensinar/aprender - construção do conhecimento cotidiano, escolar e científico - ocorre através de relações interativas entre professor e alunos e entre os alunos, que podem ser integradas à exploração de atividades construtivistas." (MENDES, 2001, p. 22).

Partindo dessas considerações acreditamos que o desenvolvimento de atividades propostas no ensino da matemática com atividades históricas via artefatos históricos, pode ajudar na construção do conhecimento por parte do aluno, haja vista que, a avaliação positiva dos alunos em relação a essa questão.

Também observamos que a história da matemática pouco é abordada em sala de aula. Assim, de acordo com Mendes (2001, p. 19), “[...] as informações históricas raramente são utilizadas como elemento gerador da aprendizagem da matemática, quer seja na ação pedagógica do professor, quer seja nos livros adotados por ele."

Nesse sentido, é interessante que os professores criem possibilidades de ensino em sala de aula com o auxílio da história da matemática e uma dessas possibilidades são os artefatos históricos. Assim, o trabalho com atividades históricas via artefatos na EJA foi avaliado como positivo, pois propiciou que os alunos fizessem reflexões sobre os conteúdos matemáticos.

\section{Considerações finais}

Concluímos em nossa análise que os alunos não têm experiência com o uso da história da matemática e têm dificuldades em associar a história e os conteúdos matemáticos.

Com relação às atividades envolvendo a história da matemática, percebemos que é possível trabalhar com os artefatos históricos, desde que a princípio o professor faça um planejamento de como estas atividades serão desenvolvidas em sala de aula, possibilitando aos envolvidos um caminho de aprendizagem. 
Concluímos ainda que os alunos da EJA ainda apresentam muitas dificuldades em relação à aprendizagem matemática. Essa percepção deve-se ao fato de termos observado algumas dificuldades dos alunos em relação a determinados artefatos históricos. Apesar das dificuldades as aulas foram bastante produtivas e os alunos muito participativos, sempre dialogando com os colegas sobre as atividades trabalhadas em sala, mostrando ter bastante interesse em compreender os conteúdos que eram apresentados, tornando as aulas em momentos de aprendizagem para todos. Dessa forma é possível desenvolver um trabalho com a história da matemática que envolva e estimule os alunos a terem interesse nessa ciência.

A experiência dessa pesquisa nos proporcionou uma reflexão acerca de como podemos trabalhar com artefatos históricos nas aulas de Matemática e como a história da Matemática pode contribuir no processo e aprendizado do aluno, permitindo que o sujeito interaja e troque ideias com o professor e os seus colegas, fazendo assim com que as aulas sejam mais produtivas e dinâmicas.

Além disso, é importante que o professor perceba que pode utilizar a História da Matemática com outras metodologias, a exemplo dos materiais manipulativos, utilizados nesse trabalho.

\section{Referências}

BRASIL. Ministério da Educação. Proposta curricular para a educação de jovens e adultos: segundo segmento do ensino fundamental: $5^{\text {a }}$ a 8a série. Brasília: SEF, 2002.

D’AMBRÓSIO, U. A História da Matemática: Questões historiográficas e políticas e reflexivas na educação matemática. In: BICUDO. M. A. V.(Org.) Pesquisa em matemática: concepções e perspectivas. São Paulo: UNESP, 1999.

FELICIANO, L. F. O uso da história da matemática em sala de aula: o que pensam alguns professores do Ensino Básico. 171 p. Dissertação (Mestrado em Educação). Universidade Estadual Paulista Júlio de Mesquita Filho, Rio Claro, SP, 2008.

FONSECA, M. da C. F. R. Educação matemática de jovens e adultos:

Especificidades desafios e contribuições. 3. ed. Belo Horizonte: Autêntica, 2012.

FOSSA, J. A. Ensaios sobre a educação matemática. Belém: Editora da UEPA, 2001.

GIL, A. C. Como elaborar projetos de pesquisa. 4. ed. São Paulo: Atlas, 2002. 
GONÇALVES, H. de A. Manual de metodologia da pesquisa cientifica. São Paulo: Avercamp, 2005.

GUTIERRE, L. dos S. História da matemática: Atividades para sala de aula. Natal, RN: EDUFRN, 2011.

MENDES, I. A. Ensino da matemática por atividades: uma aliança entre o construtivismo e a história da matemática. 207p. Tese (Doutorado em Educação) Universidade Federal do Rio Grande do Norte. Programa de Pós-Graduação em Educação. Natal (RN), 2001.

MENDES, I. A. História da matemática em atividades didáticas. 2. ed. São Paulo: Editora Livraria da Física, 2009.

OLIVEIRA, M. M. de. Como fazer pesquisa qualitativa. Petrópolis/RJ: Vozes, 2007.

OLIVEIRA, R. L. de. Ensino de matemática, história da matemática e artefatos: possibilidades de interligar saberes em cursos de formação da educação infantil e anos iniciais do ensino fundamental. 189f. Tese (Doutorado em Educação). UFRN: Programa de Pós Graduação em Educação, 2009.

OLIVEIRA, R. L. de. Experiências de utilização de artefatos históricos em atividades de ensino. Boletim Cearense de Educação e História da Matemática. v. 4, n. 11, p. 7180, 2017.

SILVA, V. S.; NASCIMENTO, D. J. da R.; SILVA, K. L.; NASCIMENTO, M. F. G. do; ANGELO, C. B. O uso de artefatos históricos na Educação de jovens e adultos: um estudo sobre o perfil dos professores participantes. In: II Congresso Nacional de Educação - CONEDU, 2015, Campina Grande/PB. Anais... Campina Grande/PB, 2015. 